\title{
Using an LQR active anti-roll bar system to improve road safety of tractor semi-trailers
}

\author{
Vu Van Tan*, Nguyen Duy Hung
}

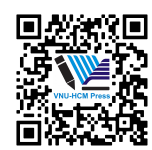

Use your smartphone to scan this QR code and download this article

\begin{abstract}
Introduction: Tractor semi-trailer vehicles are playing an increasingly important role in the global freight chain. However, due to the heavy total load and height of the center of gravity, this type of vehicle is often at a higher risk of instability than other vehicles. This paper focuses on improving the vehicle roll stability by using an active anti-roll bar system. Methods: The Linear Quadratic Regulator (LQR) approach is used for this purpose with the control signal being the torque generated by the active anti-roll bar system. In order to synthesize the controller, the roll angle of the vehicle body and the normalized load transfer at all axles of the tractor semi-trailer vehicle are considered as the optimal goals. Results: The simulation results in time and frequency domains clearly show the effectiveness of the proposed method for the active anti-roll bar system, because the reduction of the desired criterias is about $40 \%$ less when compared to a vehicle using the passive anti-roll bar system. Conclusions: The effectiveness of the active anti-roll bar system on improving the vehicle roll stability, has been verified in this theoretical study with the LQR optimal controller. This is an important basis for conducting more in-depth studies and future experiments.

Key words: Tractor semi-trailer, Road safety, Roll stability, Active anti-roll bar system, Rollover
\end{abstract}

\section{INTRODUCTION}

Road traffic accidents are one of the biggest causes of death, injuries, and public health impacts worldwide.

Department of Automotive Mechanical Engineering, Faculty of Mechanical Engineering, University of Transport and communications, Hanoi, Vietnam

Correspondence

Vu Van Tan, Department of Automotive Mechanical Engineering, Faculty of Mechanical Engineering, University of Transport and communications, Hanoi, Vietnam

Email:vvtan@utc.edu.vn

History

- Received: 2020-04-06

- Accepted: 2020-08-18

- Published: 2020-08-21

DOI : 10.32508/stdj.v23i3.2060

\section{Check for updates}

\section{Copyright}

(c) VNU-HCM Press. This is an openaccess article distributed under the terms of the Creative Commons Attribution 4.0 International license.

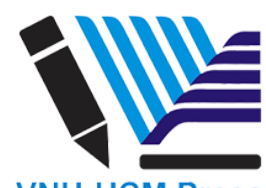

VNU-HCM Press and the heavy total load, while its width is limited to a maximum of $2.5 \mathrm{~m}$, the risk of rollover accidents for this type of vehicle type is very high, the possible reasons include adverse weather conditions, sudden braking maneuvers, avoidance of an obstacle, driver error, excess speed, jack-knifing, load, road design, suspension systems ${ }^{2,3}$. Currently, the passive AntiRoll Bar (ARB) system is used on most tractor semitrailers in order to improve the vehicle roll stability. However, theoretical and experimental research results have shown that in emergency situations, the passive ARB system does not overcome the rollover moment caused by the lateral inertia force. In order to overcome the disadvantages of the passive ARB system in avoiding rollover phenomenon, a number of active safety systems have been studied and applied in actual vehicles such as active suspension, active ARB system, active braking, and active steering. Among the above-mentioned systems, the most effective solution is the active ARB system ${ }^{4}$.

The research on controlling the active ARB system for heavy vehicles in general and the tractor semi-trailer, in particular, was carried out most prominently by a research team at the University of Cambridge in the United Kingdom. In the study of Arnaud J.P. Miège ${ }^{5}$, the author used the PID control method for a roll model with the goal of reducing the roll angle of the 


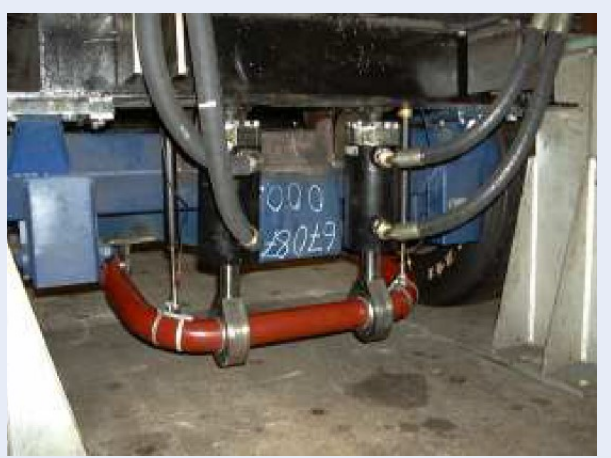

Figure 1: Description of an active ARB system ${ }^{5}$.

vehicle's body. $\mathrm{In}^{4}$, the authors proposed a semiactive ARB system by combining active and passive systems. The basic principle of this method is that when a vehicle moves around a right bend (curve) and the low damping setting is confirmed, so the vehicle starts to roll outward. If later the selection of the high damping is made, the roll outward will be locked. In 6,7 , a state feedback roll control system was designed for a tractor semi-trailer using a flexible frame, which allowed a more accurate assessment of the advantages of this system. In $^{8}$, an empirical research by the PID control method was embedded on an actual tractor semi-trailer. The control signal in this model is the spool valve displacement; the author had controlled the active ARB system to improve the vehicle roll stability. However, this experiment only shows the interaction of the vehicle in the immediate response at each axle and does not consider the dynamics of the whole vehicle. Although previous studies have shown the efficiency of the active antiroll bar system on the articulated heavy vehicles, the optimal control method has not been designed to directly optimize the criteria for evaluating the vehicle roll stability, and the comparison results with the passive system mainly appear in the time domain or in stable driving mode.

The outstanding contributions of this study are as follows:

- Building a Yaw-Roll model of a tractor semi-trailer with a total load of about 40 tons. The tractor consists of two single axles, and the three rear axles on the semi-trailer are considered as an axle in the middle.

- Designing an LQR controller to enhance the roll stability of the tractor semi-trailer, in which the normalized load transfers at all axles and the body's roll angle are the desired criteria to minimize.

- The simulation results in time and frequency domains clearly show the efficiency of the LQR active

ARB system in enhancing the roll stability. Specifically, the reduction of the amplitude of the signals is about $40 \%$ less compared to the passive system.

The paper structure consists of five sections: Section 1 introduces the concept of vehicle roll stability, as well as the major contributions of the study. Section 2 presents the Yaw-Roll model of a tractor semi-trailer with the active ARB system on all axles. The LQR controller is synthesized to improve the roll stability of the tractor semi-trailer as shown in section 3. Section 4 evaluates the simulation results on the time and frequency domains. Finally, section 5 highlights some conclusions and perspectives.

\section{VEHICLE MODELLING OF TRACTOR SEMI-TRAILER}

\section{Yaw-Roll model of a tractor semi-trailer ve- hicle}

Figure 1 illustrates a tractor semi-trailer combination, which consists of a triple axle tanker semi-trailer linked to a two axle tractor through a fifth wheel coupling. We consider the vehicle model with the lateral, yaw and roll dynamics, for studying of the rollover phenomenon. This is a linear model with the forward velocity considered constant in motion situations. It means that the forward velocity is not a state variable of the system but simply a parameter. The mathematical model of the tractor takes into consideration the flexible frame to consider the effect of the transfer between the two axles, while for simplicity this study does not consider the torsional frame of the semitrailer (rigid frame model). The parameters of the tractor and semi-trailer are shown in Appendix ${ }^{9}$.

By denoting the semi-trailer with the subscript "2", the tractor with the subscript " 1 ", the rear axle with the subscript "r", the front axle with the subscript "f", the dynamical equation of the vehicle model is presented in equations from (1) to $(12)^{9}$.

- The dynamical equations of motion for the tractor are

$$
\begin{aligned}
& \delta . N_{\delta, 1}+\dot{\psi}_{1} \cdot N_{\dot{\psi}_{1}, 1}+\beta_{1} \cdot N_{\beta_{1}, 1} \\
& -F_{c, 1} \cdot b_{r, 1}^{\prime}+k_{\psi, 1}\left(\psi_{2}-\psi_{1}\right) \\
& =\ddot{\psi} \cdot I_{z^{\prime} z^{\prime}, 1}-\ddot{\phi}_{r, 1} \cdot I_{x^{\prime}, z^{\prime}, r, 1}-\ddot{\phi}_{f, 1} \cdot I_{x^{\prime}, z^{\prime}, r, 1} \\
& l_{f, 1} \cdot\left(\dot{\phi}_{t, f, 1}-\dot{\phi}_{f, 1}\right)+k_{f, 1}\left(\phi_{t, f, 1}-\phi_{f, 1}\right) \\
& +l_{b, 1} \cdot\left(\dot{\phi}_{r, 1}-\dot{\phi}_{f, 1}\right)+k_{b, 1} \cdot\left(\dot{\phi}_{r, 1}-\dot{\phi}_{f, 1}\right) \\
& -h_{f, 1}\left(\dot{\beta}_{1}+\dot{\psi}_{1}\right) \cdot m_{s, f, 1} \cdot V+h_{f, 1} \cdot \phi_{f, 1} \cdot m_{s, f, 1} \cdot g \\
& -h_{b, 1} \cdot F_{b, 1}+T_{f}=-\ddot{\psi}_{1} \cdot I_{x^{\prime}, z^{\prime}, f, 1}+\ddot{\phi}_{f, 1} \cdot I_{x^{\prime}, x^{\prime}, f, 1}
\end{aligned}
$$




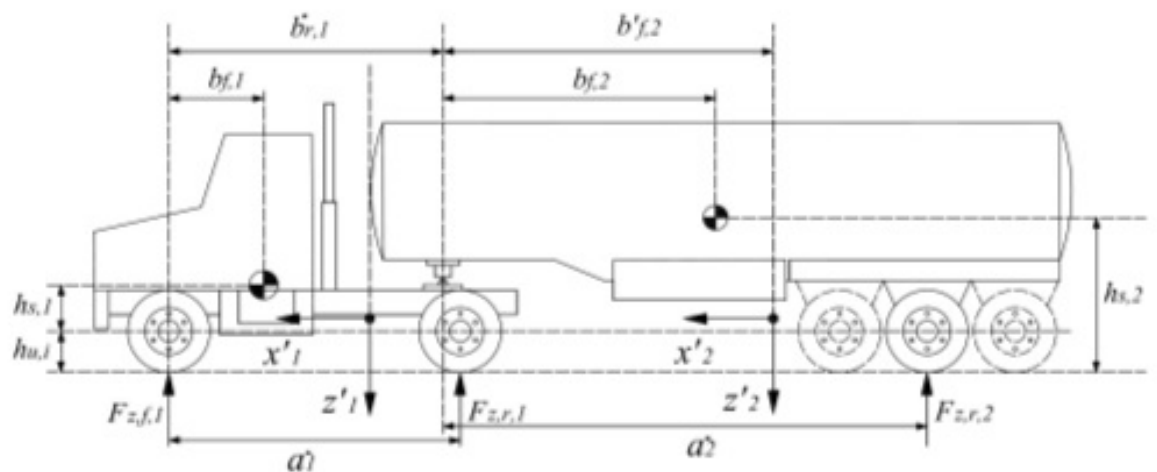

a)
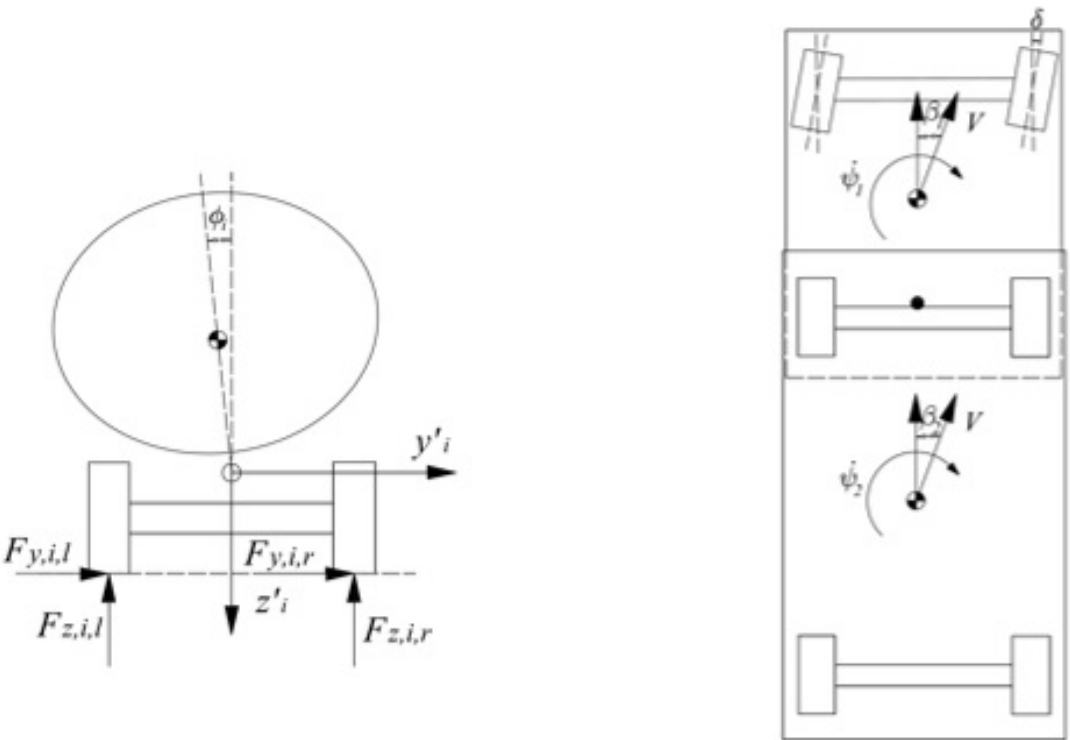

b)

c)

Figure 2: A tractor semi-trailer vehicle model: a) Longitudinal direction, b) Roll direction, c) Yaw direction.

$$
\begin{aligned}
& l_{f, 1} \cdot\left(\dot{\phi}_{t, f, 1}-\dot{\phi}_{f, 1}\right)+k_{f, 1}\left(\phi_{t, f, 1}-\phi_{f, 1}\right) \\
& +l_{b, 1} \cdot\left(\dot{\phi}_{r, 1}-\dot{\phi}_{f, 1}\right)+k_{b, 1} \cdot\left(\dot{\phi}_{r, 1}-\dot{\phi}_{f, 1}\right) \\
& -h_{f, 1}\left(\dot{\beta}_{1}+\dot{\psi}_{1}\right) \cdot m_{s, f, 1} \cdot V+h_{f, 1} \cdot \phi_{f, 1} \cdot m_{s, f, 1} \cdot g \\
& -h_{b, 1} \cdot F_{b, 1}+T_{f}=-\ddot{\psi}_{1} \cdot I_{x^{\prime}, z^{\prime}, f, 1}+\ddot{\phi}_{f, 1} \cdot I_{x^{\prime}, x^{\prime}, f, 1}
\end{aligned}
$$

$$
\begin{aligned}
& l_{f, 1} \cdot\left(\dot{\phi}_{t, f, 1}-\dot{\phi}_{f, 1}\right)+k_{f, 1} \cdot\left(\phi_{t, f, 1}-\phi_{f, 1}\right) \\
& +\phi_{t, f, 1} \cdot k_{t, f, 1}-h_{u, f, 1} \cdot \phi_{t, f, 1} \cdot m_{u, f, 1} \cdot g \\
& -m_{u, f, 1} \cdot V \cdot\left(r_{1}-h_{u, f, 1}\right)\left(\dot{\beta}_{1}+\dot{\psi}_{1}\right)-T_{f} \\
& =-\left(\beta_{1} \cdot Y_{\beta, f, 1}+\dot{\psi}_{1} \cdot Y_{\psi_{1}, f, 1}+\delta_{1} \cdot Y_{\delta, f, 1}\right) \cdot r_{1}
\end{aligned}
$$

$$
\begin{aligned}
& l_{r, 1} \cdot\left(\dot{\phi}_{t, r, 1}-\dot{\phi}_{r, 1}\right)+k_{r, 1} \cdot\left(\phi_{t, r, 1}-\phi_{r, 1}\right) \\
& +\phi_{t, r, 1} \cdot k_{t, r, 1}-h_{u, r, 1} \cdot \phi_{t, r, 1} \cdot m_{u, r, 1} \cdot g \\
& -m_{u, r, 1} \cdot V \cdot\left(r_{1}-h_{u, r, 1}\right)\left(\dot{\beta}_{1}+\dot{\psi}_{1}\right)-T_{r} \\
& =-\left(\beta_{1} \cdot Y_{\beta, r, 1}+\dot{\psi}_{1} \cdot Y_{\dot{\psi}_{1}, r, 1}\right) \cdot r_{1}
\end{aligned}
$$

- The kinematic constraint at the vehicle coupling is described by

$$
\begin{aligned}
& \dot{\beta}_{1}-\dot{\beta}_{2}+\dot{\psi}_{1}-\dot{\psi}_{2}-\left(\beta_{2}-\beta_{1}\right) \frac{\dot{V}}{V} \\
& -\left(\psi_{2}-\psi_{1}\right) \frac{\dot{V}}{V}-\ddot{\psi}_{2} \cdot \frac{b_{f, 1}^{\prime}}{V}+\ddot{\psi}_{1} \cdot \frac{b_{r, 1}^{\prime}}{V} \\
& +\ddot{\varphi}_{r, 1} \cdot \frac{\left(h_{a, r, 1}-r_{1}\right)}{V}-\ddot{\varphi}_{2} \cdot \frac{\left(h_{a, f, 2}-r_{2}\right)}{V}=0
\end{aligned}
$$


- The dynamical equations of motion for the semitrailer are

$$
\begin{aligned}
&-k_{\psi, 1} \cdot\left(\psi_{2}-\psi_{1}\right)+\dot{\psi}_{2} \cdot N_{\dot{\psi}, 2}+\beta_{2} \cdot N_{\beta, 2} \\
&+F_{c, 1} \cdot b_{f, 2}^{\prime}=\ddot{\psi}_{2} \cdot I_{z^{\prime} z^{\prime}, 2}-\ddot{\phi}_{2} \cdot I_{x^{\prime} z^{\prime}, 2} \\
& l_{r, 1} \cdot\left(\dot{\phi}_{t, r, 2}-\dot{\phi}_{2}\right)+k_{r, 2}\left(\phi_{t, r, 2}-\phi_{2}\right) \\
&+K_{\phi, 1} \cdot\left(\dot{\phi}_{2}-\dot{\phi}_{r, 1}\right)-h_{2}\left(\dot{\beta}_{2}+\dot{\psi}_{2}\right) \cdot m_{s, 2} \cdot V \\
&+h_{2} \cdot \phi_{2} \cdot m_{s, 2} \cdot g+F_{c, 1}\left(h_{a, f, 2}-r_{2}\right) \\
&+T_{f}=-\ddot{\psi}_{2} \cdot I_{x^{\prime}, z^{\prime}, 2}+\ddot{\phi}_{2} \cdot I_{x^{\prime}, x^{\prime}, 2} \\
& \quad l_{r, 2} \cdot\left(\dot{\phi}_{t, r, 2}-\dot{\phi}_{2}\right)+k_{r, 2} \cdot\left(\phi_{t, r, 2}-\phi_{2}\right) \\
&-m_{u, r, 2} \cdot V \cdot\left(r_{2}-h_{u, r, 2}\right)\left(\dot{\beta}_{2}+\dot{\psi}_{2}\right) \\
&-h_{u, r, 2} \cdot \phi_{t, r, 2} \cdot m_{u, r, 2} \cdot g+\phi_{t, r, 2} \cdot k_{t, r, 2}+T_{r, 1} \\
&=-\left(\dot{\omega}_{2} \cdot Y_{\dot{\omega}, 2}+\beta_{2} \cdot Y_{\beta, 2}\right) r_{2} \\
& \\
& \quad \beta_{2} \cdot Y_{\beta, 2}-\left(\dot{\beta}_{2}+\dot{\psi}_{2}\right) \cdot m_{2} \cdot V+\dot{\psi}_{2} \cdot Y_{\dot{\psi}, 2} \\
&+F_{c, 1}=h_{2} \cdot \ddot{\phi}_{2} \cdot m_{s, 2}
\end{aligned}
$$

- The internal, dependent, lateral forces $\mathrm{F}_{c, 1}$ and $\mathrm{F}_{b, 1}$ are defined as follows:

$$
\begin{aligned}
& F_{c, 1}=-\left(\dot{\psi}_{1} \cdot V+\dot{\beta}_{1} \cdot V+\beta_{1} \cdot \dot{V}\right) \cdot m_{1} \\
& +\delta . Y_{\delta, 1}-h_{r, 1} . \ddot{\varphi}_{r, 1} \cdot m_{s, r, 1} \\
& -h_{f, 1} \cdot \ddot{\varphi}_{f, 1} \cdot m_{s, f, 1}+\beta_{1} \cdot Y_{\beta, 1}+\dot{\psi}_{1} \cdot Y_{\dot{\psi}, 1} \\
& F_{b, 1}=-\left(\dot{\beta}_{1} \cdot V+\dot{\psi}_{1} \cdot V+\beta_{1} \cdot \dot{V}\right) \cdot m_{f, 1} \\
& -h_{f, 1} \cdot \ddot{\varphi}_{f, 1} \cdot m_{s, f, 1}-h_{f, 1} \cdot \ddot{\varphi}_{f, 1} \cdot m_{s, f, 1} \\
& +\left(\beta \cdot Y_{\beta, f, 1}+\delta \cdot Y_{\delta, f, 1}+\dot{\psi}_{1} \cdot Y_{\dot{\psi}, f, 1}\right)
\end{aligned}
$$

The system's states includes both the tractor and semitrailer, of which the tractor consists of eight variables: the sprung mass's roll angles and roll rates above the front and rear axles $\left(\phi_{f, 1}, \phi_{r, 1}\right.$, , $)$, the sideslip angle and the yaw rate $\left(\beta_{1}, \dot{\psi}_{1}\right)$, the unsprung mass's roll angles at the front and rear axles $\left(\phi_{t, f, 1}, \phi_{t, r, 1}\right)$; the semi-trailer has five variables: the sprung mass's roll angle and roll rate $\left(\phi_{2}, \dot{\psi}_{2}\right)$, the sideslip angle and the yaw rate $\left(\beta_{2}, \dot{\psi}_{2}\right)$, and the unsprung mass's roll angle $\left(\phi_{t, r, 2}\right)$. The active ARB system is arranged in all the axles, the torque control of this system generated on the two axles of the tractor is denoted $T_{f, r}$, while $T_{r 1}$ is the torque at the rear axle of the semi-trailer. This model ignores the excitation from the road surface and does not consider lateral wind, etc, so the only disturbance here is the steering angle $\delta$.

The dynamical equation of the vehicle model is written in a state-space representation (13):

$$
\left\{\begin{array}{l}
\dot{x}=A x+B_{1} w+B_{2} u \\
y=C x+D_{1} w+D_{2} u
\end{array}\right.
$$

where the state vector

$$
\begin{aligned}
& x= \\
& {\left[\phi_{f, 1} \phi_{r, 1} \dot{\phi}_{r, 1} \beta_{1} \dot{\psi}_{1} \phi_{t, f, 1} \phi_{t, r, 1} \phi_{2} \dot{\phi}_{2} \beta_{2} \dot{\psi}_{2} \phi_{t, r, 2}\right]^{T}} \\
& , \quad \text { the active torque control vector } u= \\
& {\left[\begin{array}{ccc}
T_{f} & T_{r} & T_{r, 1}
\end{array}\right]^{T} \text {, the disturbance } w=[\delta], \text { and }} \\
& A, B_{1,2}, C, D_{1,2} \text { are the matrices. }
\end{aligned}
$$

\section{Performance criteria}

The goal of the active ARB system is to improve the vehicle's roll stability thus preventing rollover in emergency situations. Equation (14) is the normalized load transfer $\left(R_{i}\right)$ commonly used to assess the rollover phenomenon. The vehicle is considered to ensure the roll stability when the value of $R_{i}$ does not exceed the limit of $\pm 1^{9,10}$.

$$
R_{i}=\frac{\triangle F_{z, i}}{F_{z a i}}
$$

where $F_{z, a, i}$ is the total axle load and $\triangle F_{z, i}$ are the lateral load transfer at one axle.

When a wheel starts to lift off from the road (loss of wheel to road contact), the value of $R_{i}$ will exceed \pm 1 , which means that the rollover phenomenon starts to occur. In addition to the above criteria, the limit of lateral acceleration $\left(a_{y}<0.5 g\right)$ and the roll angle of the suspension on each axle (7-8deg) should be minimized, however in this study, these two criteria have not been considered ${ }^{11}$.

\section{OPTIMAL CONTROLLER DESIGN FOR AN ACTIVE ANTI-ROLL BAR SYSTEM}

\section{Background on LQR control}

Equation (13) is a linear time invariant system model that characterizes the vehicle dynamics equation. We consider the full state feedback control problem and assume that all variables in the state vector can be measured by sensors or estimated, so the control vector $\mathrm{u}$ has a general form in Equation (15) with $\mathrm{K}$ being the state feedback gain matrix.

$$
u=-K x
$$

The optimization process is specifically expressed in defining the control input vector $u$ to minimize the performance index $J$ expressed in Equation (16). Note that this index includes the performance characteristics that need to be minimized, as well as input control limitations to avoid system's saturation.

$$
J=\int_{0}^{+\infty}\left(x^{T} Q x+u^{T} R u+2 x^{T} N u\right) d t
$$


where $Q, R$, and $N$ are positive definite weighting matrices. The optimal problem must be ensured that the LTI system (13) is stabilizable with the optimal controller. The state feedback gain matrix $\mathrm{K}$ is determined in the following equation ${ }^{12}$ :

$$
R^{-1} B^{T} P=K
$$

where the matrix $P$ is not randomly selected but the solution of the Riccati algebraic equation:

$$
A^{T} P+A P+Q-P B R^{-1} B^{T} P=0
$$

By combining equations (17) and (15) into equation (13), the optimal closed-loop system is rewritten in compact form as follows:

$$
\dot{x}=\left(A-B_{2} K\right) x+B_{1} w
$$

Remark 1: The choice of the control input $u$ and the state vector $x$ will greatly affect the identification of matrices $Q, R, N$.

\section{Active anti-roll bar LQR controller design}

As stated above, the main purpose of the LQR controller design is to improve the vehicle's roll stability. Two variables that need to be minimized are the roll angles $\left(\phi_{i}\right)$ and the normalised load transfers at all axles $\left(R_{i}\right)$. In addition, in order to avoid the saturation of the actuators, the magnitude of the torque control $\left(T_{f}, T_{r}, T_{r 1}\right)$ also needs to be minimized. Therefore, the performance index $J$ is selected as follows:

$$
\begin{aligned}
& J=\int_{0}^{\infty}\left(\rho_{1} \phi_{f, 1}^{2}+\rho_{2} \phi_{f, 1}^{2}+\rho_{3} \phi_{f, 2}^{2}+\rho_{4} R_{f}^{2}\right. \\
& \left.+\rho_{5} R_{r}^{2}+\rho_{6} R_{r, 1}^{2}+\lambda_{1} T_{f}^{2}+\lambda_{2} T_{r}^{2}+\lambda_{3} T_{r, 1}^{2}\right) d t
\end{aligned}
$$

where $\rho_{1}, \rho_{2}, \rho_{3}, \rho_{4}, \rho_{5}, \rho_{6}$, are called the weighting parameters of the performance index J.

The selection of the value of the weighting parameters is entirely dependent on the design purpose. When we want to increase the optimization level of a signal, we increase the value of that weighting parameter. From Equation (20), if we increase a lot of $\rho_{i}$ values, the controller will focus on improving the vehicle roll stability, if the $\lambda_{i}$ values are increased, it will be directed to the protection of the actuator to avoid overcoming its physical limitation.

\section{SIMULATION RESULTS ANALYSIS}

In this section, the forward velocity is considered constant at $60 \mathrm{~km} / \mathrm{h}$. The simulation results are shown in both frequency and time domains for the tractor semi-trailer vehicle using a full-state feedback LQR active ARB controller. The vehicle using the active ARB system is denoted by the continuous line, and the passive ARB system by the dashed line.

\section{Analysis in frequency domain}

Figure 3 shows the frequency response of the important signals to evaluate vehicle roll stability, namely the roll angles of the tractor and semi-trailer, and the normalized load transfers at all axles. In particular, the authors use the transfer function magnitude from the steering angle. Figure $3 \mathrm{a}, \mathrm{b}$ show the transfer function magnitude from the steering angle to the roll angle of the sprung mass of the tractor and semitrailer; Figure $3 \mathrm{c}$,d,e show the transfer function magnitude from the steering angle to the normalized load transfers at all axles; meanwhile, Figure $3 \mathrm{f}$ shows the transfer function magnitude from the steering angle to the torque control at three axles. For this system, the steering angle being the only excitation, the frequency range is considered up to $4 \mathrm{rad} / \mathrm{s}$, since it is specific to the driver's bandwidth frequency ${ }^{13}$. We find that when compared to a vehicle using the passive ARB system, the active ARB system with an LQR controller has reduced the roll angle of the tractor's body about $6 \mathrm{~dB}$, the semi-trailer reduction is about 5 $\mathrm{dB}$. Meanwhile, the reduction of the normalized load transfers at the front and rear axles of the tractor are about $4 \mathrm{~dB}$ and $5 \mathrm{~dB}$, the semi-trailer is $6 \mathrm{~dB}$, respectively. In addition, Figure $3 \mathrm{f}$ also clearly shows the torque control at the three axles from the active ARB system.

From the simulation results in the frequency domain, we can conclude that the tractor semi-trailer using the LQR active ARB system has improved the vehicle roll stability.

\section{Analysis in time domain}

In this section, we consider an avoiding obstacle scenario, with the specific concept of a Double Lane Change (DLC) in order to better assess the ability to improve the roll stability of the tractor semi-trailer using LQR active ARB control system. The steering angle in the DLC scenario is shown in Figure $4^{14,15}$.

Figure 5 presents the time responses of the roll angles and the normalized load transfers of both the tractor and the semi-trailer, as well as the torque controls generated from the actuators of the active ARB system on all axles. In the case of using the active ARB system, the roll angle of the tractor is reduced about $50 \%$ and $40 \%$ for the semi-trailer, as shown in Figure $5 \mathrm{a}, \mathrm{b}$. The vehicle roll stability effect is clearly shown for the normalised load transfers of the axles, as shown in Fgures $5 \mathrm{c}$,d,e. For the tractor, the normalised load transfers are reduced about 50\%,60\% for the front and rear axles, respectively. Meanwhile, 

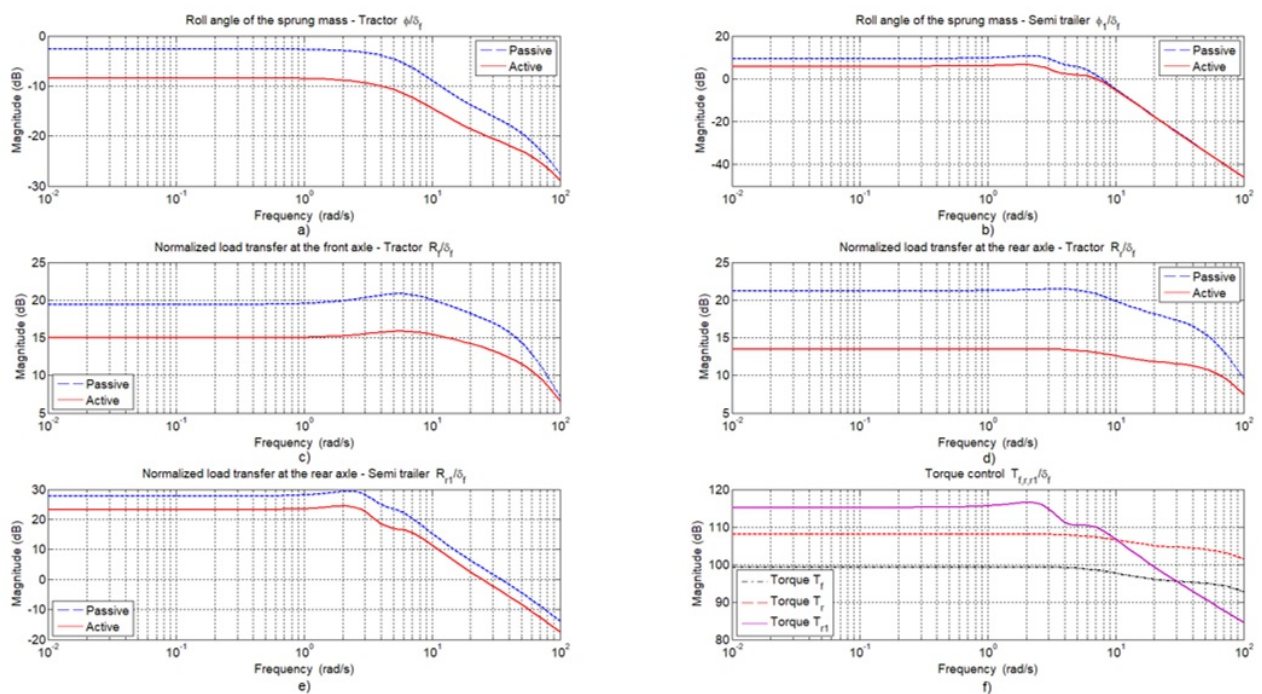

Figure 3: Frequency responses of: Roll angles of the sprung masses of tractor (a), semi-trailer (b); Normalised load transfers on the front axle (c), the rear axle (d) of tractor, on the rear axle of semi-trailer (e), Torque controls (f).

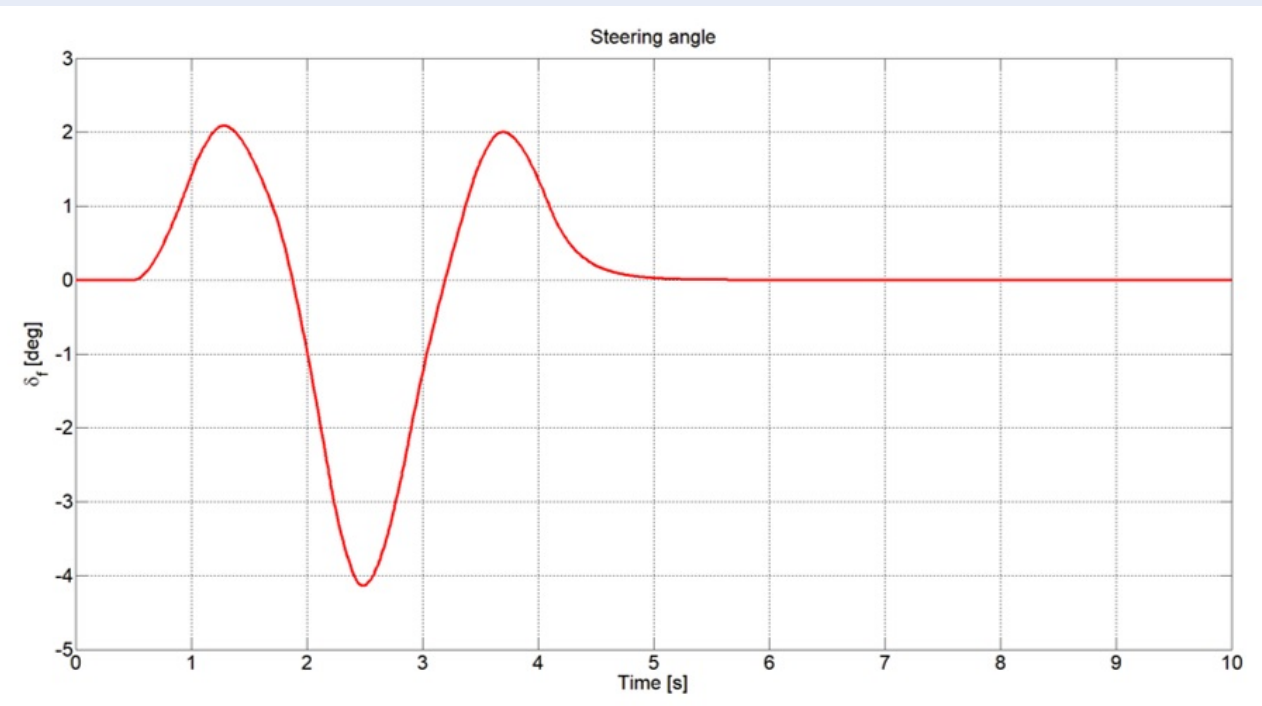

Figure 4: Time responses of the steering angle.

for the semi-trailer, the normalised load transfer is reduced about $40 \%$ when compared to the vehicle using the passive ARB system. Moreover, for the tractor semi-trailer using the passive ARB system, all three axles are lifted off from the road (the absolute value of $\mathrm{R} i$ exceeds 1 ), but at this speed of $60 \mathrm{~km} / \mathrm{h}$, the tractor semi-trailer using the active ARB system with an LQR controller still ensures good roll stability because the absolute value of $R i$ is still less than 1 .
The survey results when changing the speed with the situation of an avoiding obstacle DLC, indicate that with the passive ARB system, the tractor semi-trailer starts to be unstable when the speed is $38 \mathrm{~km} / \mathrm{h}$, while if using the LQR active ARB system with an LQR controller, the rollover phenomenon will occur when the speed is $61 \mathrm{~km} / \mathrm{h}$. Thus, the tractor semi-trailer using an active ARB system which has significantly improved the vehicle roll stability ability, and thereby preventing accidents at increased vehicle speed. 

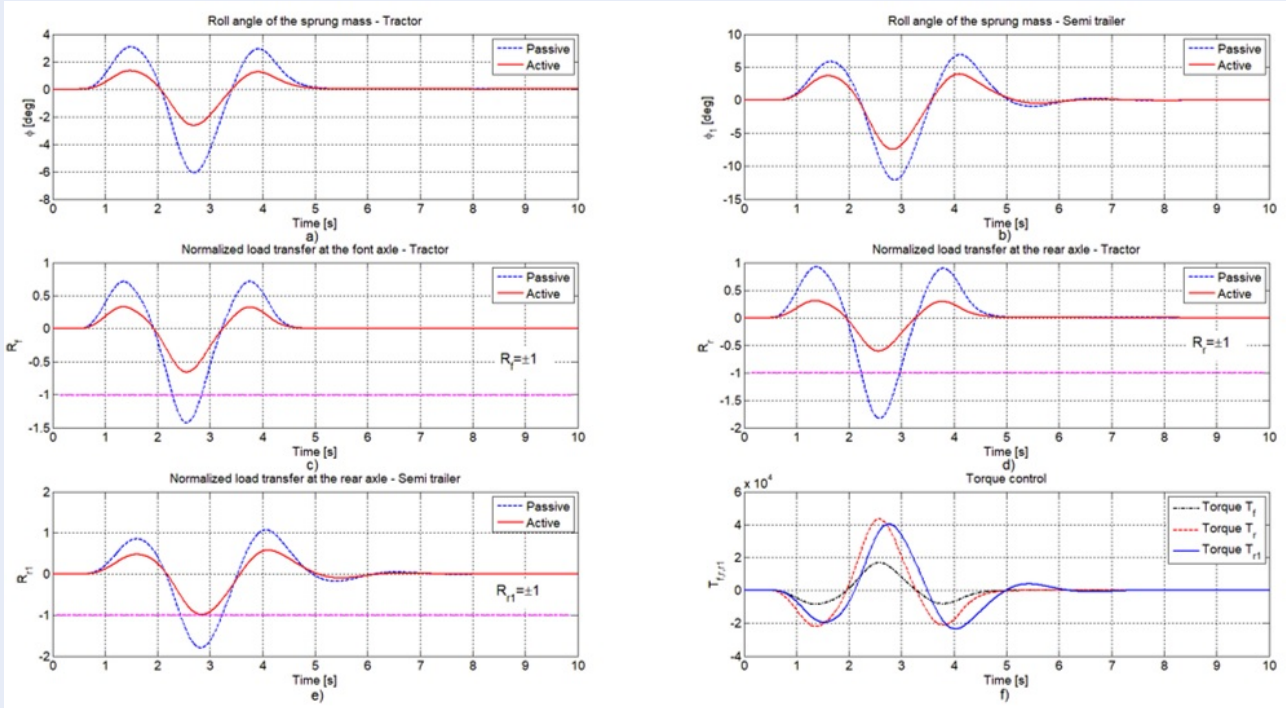

Figure 5: Time responses of: Roll angles of the sprung masses of tractor (a), semi-trailer (b); Normalised load transfers on the front axle (c), the rear axle (d) of tractor, on the rear axle of semi-trailer (e), Torque controls (f).

\section{CONCLUSION}

This paper presents the study of the active ARB system for a tractor semi-trailer by the optimal control method LQR, with the consideration of roll angle and normalized load transfer at all axles as the optimal target. The controller design using the general vehicle dynamic equations is a new direction compared to previous studies on this type of vehicle. The simulation results in time and frequency domains have shown the efficiency of reducing the amplitude value of the criteria when using the active ARB system about $40 \%$, when compared to the tractor semi-trailer using the passive ARB system. This result shows that the active ARB system is an effective solution to improve vehicle roll stability, especially for heavy tractor semitrailer type vehicles.

The next research direction of this study is to consider the changing parameters such as the vehicle velocity and the total load, or the application of advanced control methods such as robust control and LPV control method.

\section{LIST OF ABBREVIATIONS}

ARB: Anti-Roll Bar

DLC: Double Lane Change

LQR: Linear Quadratic Regulator

LTI: Linear Time Invariant

PID: Proportional Integral Derivative

WHO: World Health Organization

\section{COMPETING INTERESTS}

The authors declare that they have no competing interests.

\section{ACKNOWLEDGEMENT}

This work has been supported by the University of Transport and Communications through the key project T2019-CK-012TD.

\section{APPENDIX \\ REFERENCES}

1. Mock C, Nugent R, Kobusingye $\mathrm{O}$, Smith K. Injury Prevention and Environmental Health; 3rd edition. 2017;Available from: https://www.ncbi.nlm.nih.gov/books/NBK525218/.

2. CB Winkler, RD Ervin. Rollover of Heavy Commercial Vehicles. UMTRI-99-19 The University of Michigan. 1999;Available from: http://www.umtri.umich.edu/content/rr31_4.pdf.

3. Edwards N. Vehicle Roll-Over. Society of Operations Engineers. 2011;Available from: https://fleetassess.co.uk/wpcontent/uploads/GG-006-Vehicle-rollover-guide.pdf.

4. Stone EJ, Cebon D. Control of semi-active antiroll systems on heavy vehicles. Vehicle System Dynamics. 2010;48(10):1215-1243. Available from: https://doi.org/10.1080/00423110903427439;https: //www.tandfonline.com/doi/abs/10.1080/00423110903427439.

5. Arnaud JPM. Development of Active Anti-Roll Control for Heavy Vehicles. PhD thesis, University of Cambridge. 2000;Available from: http://arnaudmiege.co.uk/publications/ first_year_report.pdf?i=1.

6. David S, David C. An Investigation of Roll Control System Design for Articulated Heavy Vehicles. 4th International symposium on Advanced Vehicle Control, AVEC-1998, Nagoya, Japan. 1998;Available from: http://david.sampson.id.au/work/ avec-1998.pdf.

7. Hsun-Hsuan H, Rama KY, Dennis AG. Active roll control for rollover prevention of heavy articulated vehicles with multiple-rollover-index minimisation. Vehicle System Dynamics. 2012;50(3):471-493. Available from: 


\section{Table 1: Tractor's parameters}

\begin{tabular}{|c|c|c|c|}
\hline Symbols & Description & Value & Unit \\
\hline$m_{s, 1}$ & Sprung mass of Tractor & 8828 & $\mathrm{Kg}$ \\
\hline$m_{u, f, 1}$ & Unsprung mass on the front axle of theTractor & 706 & $\mathrm{Kg}$ \\
\hline$m_{u, r, 1}$ & Sprung mass on the rear axle of the Tractor & 1000 & $\mathrm{Kg}$ \\
\hline$m_{1}$ & The total Tractor mass & 10534 & $\mathrm{Kg}$ \\
\hline$V$ & Forward velocity & 60 & $\mathrm{Km} / \mathrm{h}$ \\
\hline$h_{f, 1}$ & $\begin{array}{l}\text { Height of sprung mass of front axle on the Tractor from the } \\
\text { roll axis }\end{array}$ & 1.058 & $\mathrm{~m}$ \\
\hline$h_{r, 1}$ & $\begin{array}{l}\text { Height of sprung mass of rear axle on the Tractor from the } \\
\text { roll axis }\end{array}$ & 1.058 & $\mathrm{~m}$ \\
\hline$h_{u, f, 1}$ & $\begin{array}{l}\text { Height of unsprung mass of front axle on the Tractor from } \\
\text { the ground }\end{array}$ & 0.53 & $\mathrm{~m}$ \\
\hline$h_{u, r, 1}$ & $\begin{array}{l}\text { Height of unsprung mass of rear axle on the Tractor from the } \\
\text { ground }\end{array}$ & 0.53 & $\mathrm{~m}$ \\
\hline$r_{1}$ & Height of roll axis from the ground on the Tractor & 0.742 & $\mathrm{~m}$ \\
\hline$k_{b, 1}$ & Tyre cornering roll stiffness on the front axle of the Tractor & 582000 & $\mathrm{kN} / \mathrm{rad}$ \\
\hline$l_{b, 1}$ & Tyre cornering roll damping on the front axle of the Tractor & 783000 & $\mathrm{kN} / \mathrm{rad}$ \\
\hline$k_{f, 1}$ & Suspension roll stiffness on the front axle of the Tractor & 380000 & $\mathrm{kNm} / \mathrm{rad}$ \\
\hline$k_{r, 1}$ & Suspension roll stiffness on the rear axle of the Tractor & 684000 & $\mathrm{kNm} / \mathrm{rad}$ \\
\hline$l_{f, 1}$ & Suspension roll damping on the front axle of the Tractor & 100000 & $\mathrm{kN} / \mathrm{rad}$ \\
\hline$l_{r, 1}$ & Suspension roll damping on the rear axle of the Tractor & 100000 & $\mathrm{kN} / \mathrm{rad}$ \\
\hline$k_{t, f, 1}$ & Tyre roll stiffness on the front axle of the Tractor & 2060000 & $\mathrm{kNm} / \mathrm{rad}$ \\
\hline$k_{t, r, 1}$ & Tyre roll stiffness on the rear axle of the Tractor & 3337000 & $\mathrm{kNm} / \mathrm{rad}$ \\
\hline$I_{x^{\prime} x^{\prime}, f, 1}$ & $\begin{array}{l}\text { Roll moment of inertia of sprung mass of the front axle on } \\
\text { the Tractor }\end{array}$ & 440 & $\mathrm{Kgm}^{2}$ \\
\hline$I_{x^{\prime} z^{\prime}, f, 1}$ & $\begin{array}{l}\text { Yaw-roll inertia of sprung mass of the front axle on the Trac- } \\
\text { tor }\end{array}$ & 0 & $\mathrm{Kgm}^{2}$ \\
\hline$I_{z^{\prime} z^{\prime}, f, 1}$ & $\begin{array}{l}\text { Yaw moment of inertia of sprung mass of the front axle on } \\
\text { the Tractor }\end{array}$ & 440 & $\mathrm{Kgm}^{2}$ \\
\hline$I_{x^{\prime} x^{\prime}, r, 1}$ & $\begin{array}{l}\text { Roll moment of inertia of sprung mass of the rear axle on the } \\
\text { Tractor }\end{array}$ & 563 & $\mathrm{Kgm}^{2}$ \\
\hline$I_{x^{\prime} z^{\prime}, r, 1}$ & Yaw-roll inertia of sprung mass of the rear axle on the Tractor & 0 & $\mathrm{Kgm}^{2}$ \\
\hline$I_{z^{\prime} z^{\prime}, r, 1}$ & $\begin{array}{l}\text { Yaw moment of inertia of sprung mass of the rear axle on the } \\
\text { Tractor }\end{array}$ & 563 & $\mathrm{Kgm}^{2}$ \\
\hline$b_{f, 1}$ & Length of the front axle from the Center on the Tractor & 1.95 & $\mathrm{~m}$ \\
\hline$a_{1}^{*}$ & Length of the front axle from the rear axle on the Tractor & 3.49 & $\mathrm{~m}$ \\
\hline$h_{a, r, 1}$ & $\begin{array}{l}\text { Length of roll of the coupling point from the ground on the } \\
\text { Tractor }\end{array}$ & 1.747 & $\mathrm{~m}$ \\
\hline$b_{r, 1}^{*}$ & $\begin{array}{l}\text { Length of yaw of the coupling point from the front axle on } \\
\text { the Tractor }\end{array}$ & 2.45 & $\mathrm{~m}$ \\
\hline$b_{r, 1}^{\prime}$ & $\begin{array}{l}\text { Length of yaw of the coupling point from the Center Roll on } \\
\text { the Tractor }\end{array}$ & 0.5 & $\mathrm{~m}$ \\
\hline
\end{tabular}


Table 2: Semi-Trailer's parameters

\begin{tabular}{|c|c|c|c|}
\hline Symbols & Description & Value & Unit \\
\hline$m_{s, 2}$ & Sprung mass of Semitrailer & 30821 & $\mathrm{Kg}$ \\
\hline$m_{u, r, 2}$ & Unsprung mass on the front axle of the Semitrailer & 2400 & $\mathrm{Kg}$ \\
\hline$m_{2}$ & The total mass of Semitrailer & 33221 & $\mathrm{Kg}$ \\
\hline$V$ & Forward velocity & 60 & $\mathrm{Km} / \mathrm{h}$ \\
\hline$h_{2}$ & $\begin{array}{l}\text { Height of sprung mass on the Semitrailer from the roll } \\
\text { axis }\end{array}$ & 0.658 & $\mathrm{~m}$ \\
\hline$h_{u, r, 2}$ & $\begin{array}{l}\text { Height of unsprung mass on the Semitrailer from the } \\
\text { ground }\end{array}$ & 0.53 & $\mathrm{~m}$ \\
\hline$r_{2}$ & Height of roll axis from the ground on the Semitrailer & 0.621 & $\mathrm{~m}$ \\
\hline$k_{r, 2}$ & Suspension roll stiffness of the Semitrailer & 800000 & $\mathrm{kNm} / \mathrm{rad}$ \\
\hline$l_{r, 2}$ & Suspension roll damping of the Semitrailer & 100000 & $\mathrm{kN} / \mathrm{rad}$ \\
\hline$k_{t, r, 2}$ & Tyre roll stiffness of the Semitrailer & 5328000 & $\mathrm{kNm} / \mathrm{rad}$ \\
\hline$I_{x^{\prime} x^{\prime}, 2}$ & $\begin{array}{l}\text { Roll moment of inertia of sprung mass on the Semi- } \\
\text { trailer }\end{array}$ & 20164 & $\mathrm{Kgm}^{2}$ \\
\hline$I_{x^{\prime} z^{\prime}, 2}$ & Yaw-roll inertia of sprung mass on the Semitrailer & 14577 & $\mathrm{Kgm}^{2}$ \\
\hline$I_{z^{\prime} z^{\prime}, 2}$ & $\begin{array}{l}\text { Yaw moment of inertia of sprung mass on the Semi- } \\
\text { trailer }\end{array}$ & 223625 & $\mathrm{Kgm}^{2}$ \\
\hline$a_{2}^{*}$ & $\begin{array}{l}\text { Length of yaw of the coupling point from the rear axle } \\
\text { on the Semitrailer }\end{array}$ & 7.7 & $\mathrm{~m}$ \\
\hline$b_{f, 2}$ & $\begin{array}{l}\text { Length of yaw of the coupling point from the Center } \\
\text { on the Semitrailer }\end{array}$ & 5.494 & $\mathrm{~m}$ \\
\hline$b_{f, 2}^{\prime}$ & $\begin{array}{l}\text { Length of roll of the coupling point from the Center } \\
\text { on the Semitrailer }\end{array}$ & 6.236 & $\mathrm{~m}$ \\
\hline
\end{tabular}

https://doi.org/10.1080/00423114.2011.597863;https://www. tandfonline.com/doi/abs/10.1080/00423114.2011.597863.

8. Arnaud JPM, David C. Design and Implementation of an Active Roll Control System for Heavy Vehicles. 5th International symposium on Advanced Vehicle Control, AVEC-2002, Hiroshima, Japan. 2002;Available from: https://pdfs.semanticscholar.org/ 1299/ff8579f53b3129b7a39766ba031251ba00b1.pdf.

9. Sampson DJM. Active Roll Control of Articulated Heavy Vehicles. PhD thesis; University of Cambridge, UK. 2000;Available from: http://citeseerx.ist.psu.edu/viewdoc/download?doi=10.1. $1.632 .3528 \& \mathrm{rep}=$ rep $1 \&$ type $=$ pdf.

10. Tan VV. Enhancing the roll stability of heavy vehicles by using an active anti-roll bar system. PhD thesis, University Grenoble Alpes, France. 2017;Available from: https://hal.archivesouvertes.fr/tel-01628011v2/document.

11. Gaspa P, Jozsef B, Istvan S. The Design of a Combined Control Structure to Prevent the Rollover of Heavy Vehicles. European Journal of Control. 2004;10(2):148-162. Available from: https://www.sciencedirect.com/science/article/abs/ pii/S0947358004703519https://doi.org/10.3166/ejc.10.148-162.

12. Tan VV. Olivier Sename, Luc Dugard, Peter Gáspár; Enhancing roll stability of heavy vehicle by LQR active anti-roll bar control using electronic servo-valve hydraulic actuators. Vehicle System Dynamics. 2017;55(9):1405-1429. Available from: https://www.tandfonline.com/doi/abs/10. 1080/00423114.2017.1317822? journalCode=nvsd20https: //doi.org/10.1080/00423114.2017.1317822.

13. Sampson D, Cebon D. Active Roll Control of Single Unit Heavy Road Vehicles. Vehicle System Dynamics. 2003;40(4):229-270. Available from: https://doi.org/10.1076/vesd.40.2.229.16540; https://www. tandfonline.com/doi/abs/10.1076/vesd.40.2.229.16540.

14. Tan VV. Olivier Sename, Luc Dugard, Peter Gáspár; An Investigation into the Oil Leakage Effect Inside the Electronic Servo-valve for an $\mathrm{H} \infty / \mathrm{LPV}$ Active Anti-roll Bar System. International Journal of Control, Automation and Systems. 2019;17(X). Available from: https://link.springer.com/article/ 10.1007/s12555-019-0060-2.

15. Hussain K, Stein W, Day J. Modelling Commercial Vehicle Handling and Rolling Stability; Proceedings of the Institution of Mechanical Engineers, Part K. Journal of Multi-Body Dynamics. 2005;219(4):357-369. Available from: https://doi.org/10. $1243 / 146441905 X 48707$ 